\section{The effects of shocking one member of a pair of rats*}

\author{
JOHN F. KNUTSON \\ University of Iowa, Iowa City, Iowa 52240
}

When one member of a pair of rats was insulated from electric footshock, a frequency of aggression was obtained which was far lower than that which has typically been reported in the shock-elicited aggression literature. In addition, the shocked rats developed a relatively high frequency of stereotyped responses which served as partially successful avoidance responses. These data were considered to support earlier data indicating that avoidance or escape responses to shock will take priority over attack responses to shock.

Shock-elicited aggression in rats has been shown to be altered by many environmental manipulations (Azrin, Ulrich, Hutchinson, \& Norman, 1964; Dryer \& Church, 1968; Powell \& Creer, 1969; Ulrich \& Azrin, 1962). Recently the manipulation of such subject variables as age and rearing conditions (Hutchinson, Ulrich, \& Azrin, 1965), sensory impairment (Flory, Ulrich, \& Wolff, 1965), and REM sleep deprivation (Morden, Conner, Mitchell, Dement, \& Levine, 1968) has influenced the occurrence of shock-elicited aggression in rats. Two studies have indicated that, in addition to altering those variables which influence both members of a fighting pair, altering the characteristics of one member of a fighting pair will seriously change the frequency of shock-elicited aggression. Powell, Francis, Braman, \& Schneiderman (1969) demonstrate that injecting a single member of a pair of rats with chloropromazine results in a marked reduction in the frequency of shock-elicited aggression. The Powell et al (1969) article also demonstrates the marked individual differences in shock-elicited aggression in rats, and the naturally occurring behavior of individual rats that may determine the elicited attack frequency in the pair of rats. Pairing rats obtained from low-frequency fighting pairs with rats from high-frequency fighting pairs often resulted in a low-frequency of fighting in the newly formed pairs. Ulrich \& Azrin (1962) indicated that shocking a single rat of a pair of rats resulted in a frequency of elicited aggression which was considerably lower than that which occurs when both members of a rat pair are shocked. Observations of naturally occurring aggression have indicated that often specific behaviors must be emitted by an animal before that animal will be attacked by

* This research was supported in part by funds made available by the Graduate College of the University of Iowa. The assistance of Michael Hynan in data assistance of Michael Hynan in
collection is gratefully acknowledged. Three days after being transferred from community cages to these

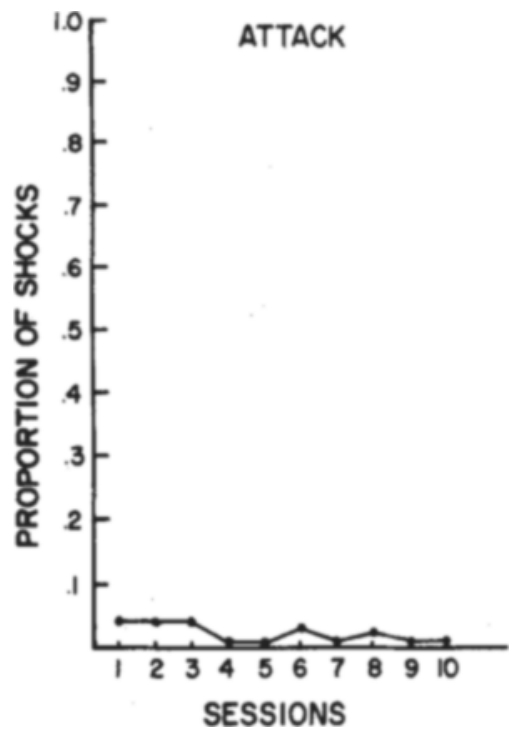
recorded until the second session. individual cages, the rats were paired according to weight. One member of each pair was randomly designated as the target.

The fighting chamber consisted of a $9 \times 1 \frac{1 / 2}{9} 7 \frac{1}{2}$ in. standard operant-conditioning chamber. Three walls and the top were constructed of Plexiglas, one wall was constructed of aluminum, and the grid floor was made of $1 / 16$-in. stainless steel rods located $1 / 2$ in. apart, center to center. The fight chamber was housed in an Industrial Acoustics Company sound-attenuating chamber. Scrambled shock was delivered by a Lehigh Valley Model 1531 constant-current shock source. Shock duration and frequency were programmed by means of conventional relay circuitry and electronic timers.

The rat designated as a target was insulated from the grid floor by means of small boots attached to the rear feet of the rat. The boots were made by covering the surface of the foot with a piece of moleskin and then attaching a small piece of tape to the bottom of the moleskin. This arrangement successfully insulated the target from the electric shock, and, although it caused his movement to be somewhat awkward, it did not eliminate mobility. The target rat was then placed in a harness consisting of two No. 62 Swingline rubber bands criss-crossed behind one leg and across the opposite shoulder. The two bands were connected to a snap swivel which was connected to a bead chain passed through a hole in the center of the chamber ceiling. The chain was drawn up sufficiently to keep the rat in the

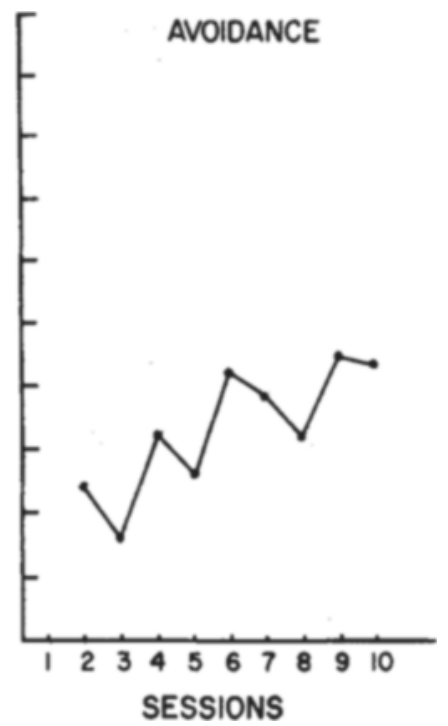

Fig. 1. The proportion of shocks which elicited aggression or were avoided during shockelicited aggression test sessions. Avoidance was not systematically 
center of the chamber and at the same time permit enough freedom to rotate about and move laterally a few inches. The harness also gave sufficient support and stability to the target so it could maintain a posture which kept the uninsulated forepaws off the grid floor.

Each experimental rat was placed in the chamber with the previously paired insulated and harnessed target rat. After $10-15 \mathrm{sec}, 5-\mathrm{sec} 2-\mathrm{mA}$ shocks were presented at a rate of 20 per minute for $10 \mathrm{~min}$. This procedure was repeated for 10 sessions over a 2 -week period. Two Es recorded the occurrence of shock-elicited aggression responses, which consisted of biting and pawing at the target rat while in the stereotyped aggressive posture (Ulrich \& Azrin, 1962). Only one response per shock was recorded.

\section{RESULTS}

Very little shock-elicited aggression occurred in this experimental situation. All Ss displayed some attack responses directed at the target, but the frequency was never more than 36 out of a possible 200 shock presentations. The initial response of the experimental rats to the shock was characterized by a high activity level, running about the chamber, rearing up on hindlegs, and often bumping into and attempting to climb on the target animal. Within the first session all rats began to display responses which developed into behavior patterns with individualized stereotyped posturing. Most frequently this response.included an upright posture, but did not include fighting. It was observed that this response was occasionally effective in preventing shock presentation to the experimental rat and, starting with the second session, shock avoidance as well as shock-elicited aggression was recorded for each $\mathrm{S}$. Fig. 1 shows the mean proportion of shocks which were avoided during the final 9 sessions and the mean proportion of shocks which elicited aggression during all 10 sessions.

It is obvious that very little shock-elicited aggression occurred in this experiment. However, the data presented in Fig. 1 suggest the acquisition of avoidance responses during this procedure. The avoidance responses typically involved the maintenance of an upright posture and balancing with only one hindleg in contact with a single floor grid. This posture was most frequently established with the experimental rat in contact with the target animal. In fact, usually the experimental rat could maintain the posture successfully only by leaning or climbing upon the other animal. What seems noteworthy in this experiment is the fact that, although the rats were developing avoidance responses, they continued to receive more than $50 \%$ of the possible shocks. Yet, even when in close proximity or even in direct contact with the target animal, there was almost no attack behavior elicited by the shock presentation.

The target rats ty pically remained in a crouched position with both uninsulated forepaws kept off the grid floor. Although they were mobile, they could not be characterized as displaying an activity level even approaching that of an unharnessed shocked rat. Also, the target rat rarely assumed an upright posture during these sessions.

\section{DISCUSSION}

This experiment replicated the finding of Ulrich \& Azrin (1962) that shocking a single member of a rat pair results in an attack frequency far lower than has been reported when both members of a pair were shocked. Similarly, these data parallel the report by Powell et al (1969) that injection of a single rat with chloropromazine seriously mitigates the frequency of footshock-elicited aggression.

The more interesting result of the experiment was the rapid acquisition of individual stereotyped responses, which served as partially successful avoidance responses. These data certainly support the position (Azrin, Hutchinson, \& Hake, 1967) that if a situation offers both fighting and escape or avoidance opportunities, a shocked rat will display a higher probability of escape or avoidance responding than attack. Even if the rat experiences a relatively high frequency of a high-intensity shock, avoidance or escape seems to be a higher probability response than attack. The avoidance behavior in the present study usually involved close physical contact between the experimental Ss and the targets. With close physical contact maximizing the opportunity for fighting, the low fighting frequency obtained seems to emphasize the priority of avoidance or escape behavior over fighting behavior.

The target rat, not receiving any shock, displayed a lowered activity level and very little rearing up on the hindlegs. This suggested that the upright posture that occurs in shocked pairs, in addition to making escape by climbing on the other rat less likely, might serve as a response which a rat must display in order to be attacked with a high frequency. Systematic investigations of the role of various target rat behaviors seems indicated in order to determine if specific target responses are necessary in the shock-elicited aggression paradigm.

\section{REFERENCES}

AZRIN, N, H, HUTCHINSON, R, R, \& HAKE, D. F. Attack, avoidance, and escape reactions to aversive shock. Journal of the Experimental Analysis of Behavior, 1967, 10,131-148.

AZRIN, N. H. ULRICH, R. E. HUTCHINSON, $\ddot{R}$. R., \& NORMAN, D. G. Effect of shock duration on shock-induced fighting. Journal of the Experimental Analysis of Behavior, 1964, 7, 9-11.

DRYER, P. I., \& CHURCH, R. Shock-induced fighting as a function of the intensity and duration of the aversive stimulus. Psychonomic Science, 1968, 10 271-272.

FLORY, R. K., ULRICH, R. E., \& WOLFF P. C. The effects of visual impairment on aggressive behavior. The Psychological Record, 1965, 15, 185-190.

HUTCHINSON, R. R., ULRICH, R. E., \& AZRIN, N. H. Effects of age and related factors on the pain-aggression reaction. Journal of Comparative \& Physiological Psy chology, 1965, 64, 351-364.

LESTER, D., \& CHESES, K. T. Effects of deprivation upon aggression in rats Psychological Reports, 1968, 22 1129-1133.

LORENZ, K. On aggression. New York: Harcourt, Brace \& World, 1966.

MORDEN B. CONNER, R MITCHELL G., DEMENT, W., \& LEVINE, S. Effects of rapid eye movement (REM) sleep deprivation on shock-induced fighting. Physiology \& Behavior, 1968, 3, 425-432. POWELL, D. A., \& CREER, T. L Interaction of developmental and environmental variables in shock-elicited aggression. Journal of Comparative \& Physiological Psychology, 1969, 69 , 219-225.

POWELL, D. A., FRANCIS, J., BRAMAN M. J., \& SCHNEIDERMAN, N Frequency of attack in shock-elicited aggression as a function of the performance of individual rats. Journal of the Experimental Analysis of Behavior, $1969,12,81 \cdot 7-823$

ULRICH, R. E., \& AZRIN, N. H. Reflexive fighting in response to aversive stimulation. Journal of the Experimental Analysis of Behavior, 1962, 5, 511-520.

WONG, SCULL \& AMSEL The effect of partial "quinine" reward on acquisition and extinction. Psychonomic Science, 1971, Vol. 18 (1) 48-49. The unit of quinine concentration should have been expressed in grains per mililiter not grams. Thus $.12 \mathrm{~g} / \mathrm{ml}$ should $\mathrm{read} .12 \mathrm{gr} / \mathrm{ml}$. 